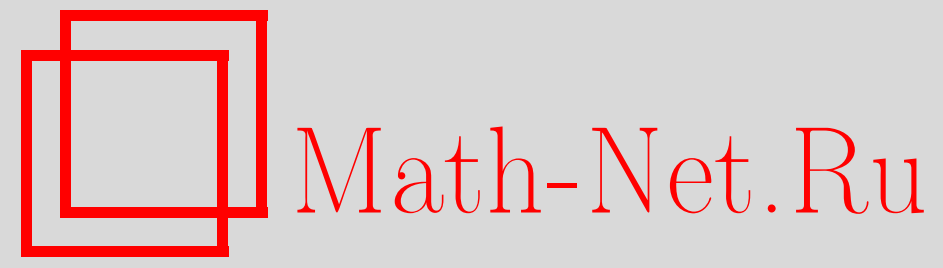

S. A. Chobanyan, Sh. Levental, H. Salehi, Maximum inequalities for rearrangements of summands and assignments of signs, Teoрия вероятн. и ее примен., 2014, том 59, выпуск 4, 800-807

DOI: https://doi.org/10.4213/tvp4598

Использование Общероссийского математического портала Math-Net.Ru подразумевает, что вы прочитали и согласны с пользовательским соглашением http://www . mathnet.ru/rus/agreement

Параметры загрузки:

IP: 3.80 .181 .102

26 апреля 2023 г., 17:41:23

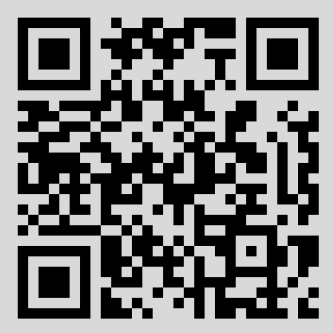


13. Лебедев А.В. Максимальные ветвящиеся процессы с неотрицательными значениями. - Теория вероятн. и ее примен., 2005, т. 50, в. 3, с. 564-570.

14. Лебедев А.В. Асимптотика хвостов стационарных распределений максимальных - Теория вероятн. и ее примен., 2009, т. 54, в. 4, с. 790-793.

15. Лебедев А.В. Максимальные ветвящиеся процессы. - Современные проблемы математики и механики, т. 4, в. 1. М: МГУ, 2009, с. 93-104.

16. Лебедев A. В. Предельные теоремы для стационарных распределений максимальных ветвящихся процессов с двумя типами частиц. - Современные проблемы математики и механики, т. 7, в. 1. М: МГУ, 2011, с. 29-38.

17. Лебедев A. В. Многотипные максимальные ветвящиеся процессы с копулами экстремальных значений. - Современные проблемы математики и механики, т. 7 , в. 1. М: МГУ, 2011, с. 39-49.

18. Лебедев А.В. Максимальные ветвящиеся процессы с несколькими типами частиц. - Вестник МГУ. Сер. 1. Матем. мех., 2012, № 3, с. 8-13.

19. Menshikov M. V., Vachkovskaia M., Wade A.R. Asymptotic behaviour of randomly reflecting billiards in unbounded tubular domains. - J. Stat. Phys., 2008, v. 132, p. 1097-1133.

20. Menshikov M.V., Wade A.R. Rate of escape and central limit theorem for the supercritical Lamperti problem. - Stoch. Proc. Appl., 2010, v. 120, p. 2078-2099.

21. Ney P., Nummelin E. Markov additive processes II. Large deviations. - Ann. Probab., 1987, v. 15, p. 593-609.

\section{MAXIMUM INEQUALITIES FOR REARRANGEMENTS OF SUMMANDS AND ASSIGNMENTS OF SIGNS ${ }^{1)}$}

В статье изучается взаимосвязь между расстановками знаков и перестановками слагаемых в форме вероятностных максимальных неравенств. Взаимосвязь основана на лемме, сводящей задачу о перестановках к задаче о выборе знаков. Наряду с упрощением известных доказательств, она позволяет находить новые факты, а также решения в более общих постановках. Одним из главных результатов статьи является следующее неравенство. Пусть $x_{1}, \ldots, x_{n}, \sum_{k=1}^{n} x_{k}=$ 0 , - набор элементов нормированного пространства $X$. Тогда для любого набора знаков $\theta=\left(\theta_{1}, \ldots, \theta_{n}\right)$ и любого $t>0$

$$
\mathbf{P}\left\{\pi: \max _{1 \leqslant k \leqslant n}\left\|\sum_{1}^{k} x_{\pi(i)}\right\|>t\right\} \leqslant C \mathbf{P}\left\{\pi: \max _{1 \leqslant k \leqslant n}\left\|\sum_{1}^{k} x_{\pi(i)} \theta_{i}\right\|>\frac{t}{C}\right\},
$$

где $\pi \in \Pi_{n}, \Pi_{n}$ - группа всех перестановок отрезка $\{1, \ldots, n\}$, $\mathbf{P}$ - равномерное распределение на $\Pi_{n}$ и $C$ - абсолютная константа. Приведенное неравенство неулучшаемо (обратное неравенство также справедливо с некоторой другой абсолютной константой). Оно обобщает известные результаты Гарсия, Морэ и Пизье, Кашина и Саакяна,

* Институт вычислительной математики им. Н. И. Мусхелишвили Грузинского технического университета, Грузия; e-mail: chobanyan@stt.msu.edu

** Department of Probability and Statistics, Michigan State University; e-mail: levental@stt.msu.edu; salehi@stt.msu.edu

1) Работа написана при поддержке Georgian Rustaveli Foundation grant FR/539/5$100 / 13$. 
Чобаняна и Салехи, и Левенталя. Все результаты настоящей статьи могут быть сформулированы на языке перестановочных случайных величин.

Ключевые слова и фразы: перестановки слагаемых, расстановки знаков, вероятностные максимальные неравенства, перестановочные случайные величины.

1. Introduction. The main aim of this paper is to study the distribution of the random variable

$$
\left|x_{\pi}\right|_{n}=\max _{1 \leqslant k \leqslant n}\left\|\sum_{1}^{k} x_{\pi(i)}\right\|
$$

where $x_{1}, \ldots, x_{n} \in X, X$ is a normed space, that is defined on $\Pi_{n}$, the set of all permutations $\pi$ of $\{1, \ldots, n\}$, with the uniform probability $\mathbf{P}$ on it. We suggest a method that allows to reduce a rearrangement problem to a problem of choosing signs (Lemma 1). It allows to simplify proofs and find new facts and statements. Although the results are stated for vectors, all of them are purposeful for the case of reals.

There are a series of problems and results in analysis where rearrangement maximum inequalities involving $\left|x_{\pi}\right|_{n}$ are used, see, e.g., the following sources and the literature therein: the Lévy-Steinitz theorem on the sum range of a conditionally convergent series (see [1]), Nikishin type theorems on a.s. convergence of a rearranged functional series (see [2]), orthogonal series (see [3]), Kolmogorov conjecture on systems of convergence (see [4]), the Ulyanov problem on the uniform convergence of a rearrangement of the trigonometric Fourier series of a periodic continuous function (see [5], [6], and [7]) and the applications of compact vector summation in scheduling theory (see [8]).

The first result in this direction was found by M. Kadets [9] who was solving the Steinitz problem for the $L_{p}$-spaces. Garsia in [10] and [11] proved that in the onedimensional case $\left(X=\mathbf{R}^{1}\right)$ for any $x_{1}, \ldots, x_{n} \in X$ with $\sum_{1}^{n} x_{i}=0$

$$
\mathbf{E}_{\pi}\left|x_{\pi}\right|_{n}^{p} \leqslant C_{p}\left(\sum_{1}^{n}\left|x_{i}\right|^{2}\right)^{p / 2}
$$

where $\mathbf{E}_{\pi}$ is the average (expectation), $p \geqslant 1$, and $C_{p}$ is a constant dependent only on $p$. This inequality led to the well-known Garsia theorem on a.s. convergent rearrangement of an orthogonal series.

Maurey and Pisier [12] were the first who showed the relationship between the permutations and signs. They proved that in the general case of a normed space $X$ for any $x_{1}, \ldots, x_{n} \in X$ with $\sum_{1}^{n} x_{i}=0$ and for any $p \geqslant 1$

$$
\mathbf{E}_{\pi}\left|x_{\pi}\right|_{n}^{p} \sim \mathbf{E}_{r}\left\|\sum_{1}^{n} x_{i} r_{i}\right\|^{p},
$$

where $r_{1}, \ldots, r_{n}$ are Rademacher random variables. The relation of equivalence in (1.1) means that ratios are bounded by positive constants dependent only on $p$. It is amazing that for a long time (until early 90s), the result of Maurey and Pisier remained unknown. Meanwhile Kashin and Saakyan [3] have proved the following result for $X=\mathbf{R}^{1}$ in terms of distributions: There is a universal constant $C$ such that for any $t>0$ and any reals $x_{1}, \ldots, x_{n}$ with $\sum_{1}^{n} x_{i}=0$ the right-hand side fragment of the following inequality holds:

$$
\mathbf{P}_{r}\left\{\omega:\left\|\sum_{1}^{n} x_{i} r_{i}(\omega)\right\|>2 t\right\} \leqslant \mathbf{P}_{\pi}\left\{\pi:\left|x_{\pi}\right|_{n}>t\right\} \leqslant C \mathbf{P}_{r}\left\{\omega:\left\|\sum_{1}^{n} x_{i} r_{i}(\omega)\right\|>\frac{t}{C}\right\} .
$$

However, the method used in [3] does not work in the case of vectors. Then Chobanyan [13] and Chobanyan and Salehi [14] used a different method to assert the left-hand side 
part and prove the two-sided inequality (1.2) for a general normed space $X$. In [15] for the case $x_{i}= \pm 1$ and in [16] for the case of $\mathbf{R}^{1}$ the inequality (1.2) was given the following form: There are universal constants $C_{1}$ and $C_{2}$ such that for any reals $x_{1}, \ldots, x_{n}$ with $\sum_{1}^{n} x_{i}=0$, any collection of signs $\theta=\left(\theta_{1}, \ldots, \theta_{n}\right)$, and any $t>0$ the following two-sided inequality holds:

$$
C_{1} \mathbf{P}\left\{\pi:\left|x_{\pi} \theta\right|_{n}>\frac{t}{C_{1}}\right\} \leqslant \mathbf{P}\left\{\pi:\left|x_{\pi}\right|_{n}>t\right\} \leqslant C_{2} \mathbf{P}\left\{\pi:\left|x_{\pi} \theta\right|_{n}>\frac{t}{C_{2}}\right\},
$$

where

$$
\left|x_{\pi} \theta\right|_{n}=\max _{1 \leqslant k \leqslant n}\left|x_{\pi(1)} \theta_{1}+\cdots+x_{\pi(k)} \theta_{k}\right| .
$$

Inequality (1.3) can be regarded as a refinement of (1.2) because its most important righthand fragment holds for each $\theta$, no average is taken with respect to $\theta$. In this paper we extend this result to the case of a normed space $X$. As a corollary we single out the following curious result: There exist universal constants $C_{1}$ and $C_{2}$ such that for any collection $x=\left(x_{1}, \ldots, x_{n}\right)$ with $\sum_{1}^{n} x_{i}=0$ in an arbitrary normed space, any collection of signs $\theta=\left(\theta_{1}, \ldots, \theta_{n}\right)$ and any $t>0$ the following two-sided inequalities hold for the distribution of a Rademacher sum:

$$
C_{1} \mathbf{P}\left\{\pi:\left|x_{\pi} \theta\right|_{n}>\frac{t}{C_{1}}\right\} \leqslant \mathbf{P}\left\{\omega:\left\|\sum_{1}^{n} x_{i} r_{i}(\omega)\right\| \geqslant t\right\} \leqslant C_{2} \mathbf{P}\left\{\pi:\left|x_{\pi} \theta\right|_{n}>\frac{t}{C_{2}}\right\} .
$$

Let us note that inequality (1.3) (as well as the majority of inequalities of this paper) can be expressed in terms of exchangeable random variables: There are universal constants $C_{1}$ and $C_{2}$ such that for any finite exchangeable system $\xi=\left(\xi_{1}, \ldots, \xi_{n}\right)$ with $\sum_{1}^{n} \xi_{i}=0$ of $X$-valued random variables, any collection of signs $\theta=\left(\theta_{1}, \ldots, \theta_{n}\right)$ and any $t>0$ the following two-sided inequality holds:

$$
\begin{gathered}
C_{1} \mathbf{P}\left\{\omega: \max _{1 \leqslant k \leqslant n}\left\|\sum_{1}^{k} \xi_{l}(\omega) \theta_{l}\right\|>\frac{t}{C_{1}}\right\} \leqslant \mathbf{P}\left\{\omega: \max _{1 \leqslant k \leqslant n}\left\|\sum_{1}^{k} \xi_{l}(\omega)\right\|>t\right\} \\
\leqslant C_{2} \mathbf{P}\left\{\omega: \max _{1 \leqslant k \leqslant n \mid}\left\|\sum_{1}^{k} \xi_{l}(\omega) \theta_{l}\right\|>\frac{t}{C_{2}}\right\} .
\end{gathered}
$$

In Section 2 we give a proposition (Lemma 1) first proved in [13] and [14], which in particular simplifies the proofs of moment maximum inequalities (among them the Maurey and Pisier core result [12] and Garsia's inequalities [11], see Section 3), and allows to state them in terms of general convex increasing functions. Theorem 1 of Section 3 represents a new idea in maximum inequalities. It suggests also a maximum inequality for finite exchangeable systems of random variables. The idea is developed in Section 4, where we give the proof of one of the main theorem on two-sided inequalities for the tail probabilities that lead via the integration by parts formula to moment inequalities for arbitrary increasing continuous functions.

2. Preliminaires. Everywhere in this paper $X$ will stand for a normed linear space, real or complex, $\Pi_{n}$ for all permutations $\pi$ of $\{1, \ldots, n\}, \mathbf{P}$ for the uniform distribution on $\Pi_{n}$, and $\Theta_{n}$ for all collections of signs $\theta=\left(\theta_{1}, \ldots, \theta_{n}\right), \theta_{i}= \pm 1, i=1, \ldots, n, n \in \mathbf{N}$.

Given $x=\left(x_{1}, \ldots, x_{n}\right) \in X^{n}, \pi \in \Pi_{n}$, and $\theta=\left(\theta_{1}, \ldots, \theta_{n}\right) \in \Theta_{n}$ we denote

$$
\left|x_{\pi} \theta\right|_{n}=\max _{1 \leqslant k \leqslant n}\left\|x_{\pi(1)} \theta_{1}+\cdots+x_{\pi(k)} \theta_{k}\right\| .
$$

In particular,

$$
|x|_{n}=\max _{1 \leqslant k \leqslant n}\left\|x_{1}+\cdots+x_{k}\right\| .
$$

Let $\pi \in \Pi_{n}$ be a permutation with $\pi=\left(k_{1}, \ldots, k_{n}\right)$ and let $\theta \in \Theta_{n}$ with

$$
\theta_{u_{1}}=+1, \ldots, \quad \theta_{u_{s}}=+1 ; \quad \theta_{v_{1}}=-1, \ldots, \quad \theta_{v_{t}}=-1,
$$


where $u_{1}<u_{2}<\cdots<u_{s}$ and $v_{1}<v_{2}<\cdots<v_{t} ; s+t=n$ are disjoint subsets of $\{1, \ldots, n\}$. Below we use the permutation $\pi^{*}(\pi, \theta)$ defined as follows:

$$
\pi^{*}=\left(k_{u_{1}}, k_{u_{2}}, \ldots, k_{u_{s}}, k_{v_{t}}, k_{v_{t-1}}, \ldots, k_{v_{1}}\right) .
$$

$\pi_{o} \in \Pi_{n}$ will denote an optimal permutation, i.e., a permutation such that $\left|x_{\pi_{0}}\right|_{n} \leqslant\left|x_{\pi}\right|_{n}$ for any $\pi \in \Pi_{n}$.

In proofs below we will use repeatedly the following lemma (see [13], [14]).

Lemma 1. (i) If $\left(x_{1}, \ldots, x_{n}\right) \in X^{n}$ with $\sum_{1}^{n} x_{i}=0$ and $\theta \in \Theta_{n}$, then

$$
\left|x_{\pi}\right|_{n}+\left|x_{\pi} \theta\right|_{n} \geqslant 2\left|x_{\pi^{*}}\right|_{n} \geqslant\left|x_{\pi} \theta\right|_{n} .
$$

(ii) For any $\theta \in \Theta_{n}$

$$
\left|x_{\pi_{o}}\right| \leqslant\left|x_{\pi_{o}} \theta\right| .
$$

To make the presentation self-contained we repeat a simple proof here.

P r o o f. Using the fact that $|\cdot|_{n}$ is a norm in $X^{n}$ we get

$$
\left|x_{\pi}\right|_{n}+\left|x_{\pi} \theta\right|_{n} \geqslant 2\left|x_{\pi}^{+}\right|_{s} ; \quad\left|x_{\pi}\right|_{n}+\left|x_{\pi} \theta\right|_{n} \geqslant 2\left|x_{\pi}^{-}\right|_{t},
$$

where $x_{\pi}^{+}=\left(x_{\pi\left(u_{1}\right)}, \ldots, x_{\pi\left(u_{s}\right)}\right)$ and $x_{\pi}^{-}=\left(x_{\pi\left(v_{1}\right)}, \ldots, x_{\pi\left(v_{t}\right)}\right)$, where $u_{1}<\ldots<u_{s}$ and $v_{1}<\cdots<v_{t}$ are the indices, where $\theta$ is positive and negative, respectively.

Now (2.1) implies

$$
\left|x_{\pi}\right|_{n}+\left|x_{\pi} \theta\right|_{n} \geqslant 2 \max \left(\left|x_{\pi}^{+}\right|_{s},\left|x_{\pi}^{-}\right|_{t}\right) .
$$

Obviously, we also have $\left|x_{\pi} \theta\right|_{n} \leqslant 2 \max \left(\left|x_{\pi}^{+}\right|_{s},\left|x_{\pi}^{-}\right|_{t}\right)$. It is easy to make sure that $\max \left(\left|x_{\pi}^{+}\right|_{s},\left|x_{\pi}^{-}\right|_{t}\right)=\left|x_{\pi^{*}}\right|_{n}$. This equality along with (2.2) gives (i). Statement (ii) is an immediate consequence of (i).

3. The moment maximum inequalities for exchangeable random variables. A finite collection $\xi=\left(\xi_{1}, \ldots, \xi_{n}\right)$ of $X$-valued random variables is called exchangeable, if for each $\pi \in \Pi_{n}$ the rearranged collection $\left(\xi_{\pi(1)}, \ldots, \xi_{\pi(n)}\right)$ has the same distribution in $X^{n}$ as $\left(\xi_{1}, \ldots, \xi_{n}\right)$.

Theorem 1. Let $\xi=\left(\xi_{1}, \ldots, \xi_{n}\right)$ be an exchangeable system of $X$-valued random variables with $\sum_{1}^{n} \xi_{i}=0$, and let $\Phi:[0, \infty) \rightarrow[0, \infty)$ be a convex increasing function. Then

(i) For any collection $\theta=\left(\theta_{1}, \ldots, \theta_{n}\right) \in \Theta_{n}$ the following two-sided inequality holds:

$$
\mathbf{E} \Phi\left(\frac{1}{2}|\xi \theta|_{n}\right) \leqslant \mathbf{E} \Phi\left(|\xi|_{n}\right) \leqslant \mathbf{E} \Phi\left(|\xi \theta|_{n}\right),
$$

where as before $|\xi \theta|_{n}=\max _{1 \leqslant k \leqslant n}\left\|\sum_{1}^{k} \xi_{i} \theta_{i}\right\|$.

(ii) The following two-sided inequality holds:

$$
\mathbf{E} \mathbf{E}_{r} \Phi\left(\frac{1}{2}\left\|\sum_{1}^{n} \xi_{i} r_{i}\right\|\right) \leqslant \mathbf{E} \Phi\left(|\xi|_{n}\right) \leqslant 2 \mathbf{E ~ E ~}_{r} \Phi\left(\left\|\sum_{1}^{n} \xi_{i} r_{i}\right\|\right),
$$

where $r_{1}, \ldots, r_{n}$ is a system of Rademacher random variables (independent random variables taking values +1 and -1 with probabilities $1 / 2$ and $1 / 2$, respectively) independent of $\xi$.

P r o o f. Since $\Phi$ is monotone and convex, we get using Lemma 1

$$
\Phi\left(|\xi \theta|_{n}\right) \geqslant \Phi\left(2\left|\xi_{\pi^{*}}\right|_{n}-|\xi|_{n}\right) \geqslant 2 \Phi\left(\left|\xi_{\pi^{*}}\right|_{n}\right)-\Phi\left(|\xi|_{n}\right) .
$$

Taking expectation of both sides and using the fact that $\xi$ is an exchangeable system, we come to the right-hand fragment of (i). The left-hand fragment of (i) also follows from Lemma 1:

$$
\mathbf{E} \Phi\left(\frac{1}{2}|\xi \theta|_{n}\right) \leqslant \mathbf{E} \Phi\left(\frac{1}{2}\left(\left|\xi^{+}\right|_{s}+\left|\xi^{-}\right|_{t}\right)\right) \leqslant \mathbf{E} \Phi\left(\left|\xi_{\pi^{*}}\right|_{n}\right) .
$$


Part (ii) follows from (i) by integrating with respect to the Rademacher random variables and using the Lévy inequality.

$\mathrm{R}$ e $\mathrm{m}$ a $\mathrm{r} \mathrm{k}$. The fact that for exchangeable $X$-valued random variables $\xi_{1}, \ldots, \xi_{n}$ with $\sum_{1}^{n} \xi_{i}=0$

$$
c_{p} \leqslant \frac{\mathbf{E} \max _{1 \leqslant k \leqslant n}\left\|\sum_{1}^{k} \xi_{i}\right\|^{p}}{\mathbf{E E}_{r}\left\|\sum_{1}^{n} \xi_{k} r_{k}\right\|^{p}} \leqslant C_{p},
$$

where $1 \leqslant p<\infty, c_{p}>0, C_{p}>0$ are constants dependent only on $p$, was found by Maurey and Pisier [12] by use of combinatorial arguments.

Let $x=\left(x_{1}, \ldots, x_{n}\right) \in X^{n}$ and consider the following random variables on the probability space $\left(\Pi_{n}, \mu\right)$, where $\mu$ is the uniform distribution on $\Pi_{n}$ :

$$
\xi_{k}(\pi)=x_{\pi(k)}, \quad \pi \in \Pi_{n}, \quad k=1, \ldots, n .
$$

Obviously, $\xi=\left(\xi_{1}, \ldots, \xi_{n}\right)$ is a system of exchangeable random variables and Theorem 1 for it can be rewritten as follows.

Corollary 1. Let $\Phi:[0, \infty) \rightarrow[0, \infty)$ be a convex increasing function, let $x=$ $\left(x_{1}, \ldots, x_{n}\right)$ be a collection of elements in $X$ with $\sum_{1}^{n} x_{i}=0$. Then

(i) For any collection $\theta=\left(\theta_{1}, \ldots, \theta_{n}\right) \in \Theta_{n}$ the following two-sided inequality holds:

$$
\mathbf{E}_{\pi} \Phi\left(\frac{1}{2}\left|x_{\pi} \theta\right|_{n}\right) \leqslant \mathbf{E}_{\pi} \Phi\left(\left|x_{\pi}\right|_{n}\right) \leqslant \mathbf{E}_{\pi} \Phi\left(|x \theta|_{n}\right) ;
$$

(ii) The following two-sided inequality holds:

$$
\mathbf{E}_{r} \Phi\left(\frac{1}{2}\left\|\sum_{1}^{n} x_{i} r_{i}\right\|\right) \leqslant \mathbf{E}_{\pi} \Phi\left(\left|x_{\pi}\right|_{n}\right) \leqslant 2 \mathbf{E}_{r} \Phi\left(\left\|\sum_{1}^{n} x_{i} r_{i}\right\|\right) .
$$

The estimating quantity $\mathbf{E} \Phi\left(\left\|\sum_{1}^{n} x_{k} r_{k}\right\|\right)$ can be expressed effectively through the coefficients $x_{k}, k=1, \ldots, n$, for Banach lattices do not containing $l_{\infty}^{n}$ uniformly (see [2] and the references therein). In the following corollary we give only the simple and popular case of a Hilbert space involving well-known Garsia's maximum inequalities.

Corollary 2. Let $\mathbf{H}$ be a Hilbert space and $x=\left(x_{1}, \ldots, x_{n}\right) \in \mathbf{H}^{n}$. Then for any $p$, $1 \leqslant p<\infty$, the following maximum inequality holds:

$$
c_{p}\left(\sum_{1}^{n}\left\|x_{k}\right\|^{2}\right)^{p / 2} \leqslant \frac{1}{n !} \sum_{\pi}\left|x_{\pi}\right|_{n}^{p} \leqslant C_{p}\left(\sum_{1}^{n}\left\|x_{k}\right\|^{2}\right)^{p / 2},
$$

where $c_{p}$ and $C_{p}$ are constants.

The right-hand side fragment of inequality (3.1) was proved by Garsia [10] for the case of real $x_{k}$.

In the following section we give a maximum inequality for the tail probabilities that allow to get two-sided maximum inequalities (analogs of Theorem 1) for any continuous increasing $\Phi$ (not only convex).

4. The main theorem. In this section we prove the main theorem of this note.

Theorem 2. Let $\xi=\left(\xi_{1}, \ldots, \xi_{n}\right)$ be an exchangeable system of $X$-valued random variables with $\sum_{1}^{n} \xi_{i}=0$. Then for any collection $\theta=\left(\theta_{1}, \ldots, \theta_{n}\right) \in \Theta_{n}$ and any $t>0$ the following two-sided inequality holds:

$$
\mathbf{P}_{1}\left(|\xi \theta|_{n}>2 t\right) \leqslant \mathbf{P}_{1}\left(|\xi|_{n}>t\right) \leqslant 2 \mathbf{P}_{1}\left(|\xi \theta|_{n}>\frac{t}{22}\right) .
$$


We will prove the following equivalent form of Theorem 2 .

Theorem 2'. Let $x=\left(x_{1}, \ldots, x_{n}\right) \in X^{n}$ be such that $\sum_{1}^{n} x_{i}=0$. Then for any collection $\theta=\left(\theta_{1}, \ldots, \theta_{n}\right) \in \Theta_{n}$ and any $t>0$ the following two-sided inequality holds:

$$
\mathbf{P}\left\{\pi:\left|x_{\pi} \theta\right|_{n}>2 t\right\} \leqslant \mathbf{P}\left\{\pi:\left|x_{\pi}\right|_{n}>t\right) \leqslant 2 \mathbf{P}\left\{\pi:\left|x_{\pi} \theta\right|_{n}>\frac{t}{22}\right\} .
$$

In Theorem $2^{\prime} \mathbf{P}$, as before, stands for the uniform distribution on $\Pi_{n}$; in Theorem 2 $\mathbf{P}_{1}$ is the probability of the underlying probability space.

The proof of the left-hand side inequality is an immediate consequence of Lemma 1 (i). The proof of the right-hand side inequality of Theorem $2^{\prime}$ is based on the following Lemmas 2-6 in what follows. Let $y=\left(y_{1}, \ldots, y_{n}\right) \in X^{n}$ and let $t>0$ be a fixed number. Denote by $\mathscr{R}$ the set of all rearrangements of $\left(y_{1}, \ldots, y_{n}\right)$ and introduce the cyclic transformation $T$ by

$$
T\left(\left(z_{1}, \ldots, z_{n}\right)\right)=\left(z_{n}, z_{1}, \ldots, z_{n-1}\right), \quad z \in \mathscr{R} .
$$

Lemma 2. Assume $\left\|y_{1}+\cdots+y_{n}\right\|<t$ and let $z \in \mathscr{R}$ be such that $|z-y|<C t$, where $C$ is a positive number. Then there is a number $k, k \in\{0,1, \ldots n-1\}$, such that

(i) $\left|y-T^{k} y\right|_{n} \geqslant|y|_{n}-t$;

(ii) $\left|z-T^{k} z\right|_{n} \geqslant|z|_{n}-(1+4 C) t$.

$\mathrm{Pr}$ o o f of $\mathrm{L}$ e $\mathrm{m} \mathrm{m}$ a 2. (i) We have

$$
\frac{1}{n} \sum_{k=0}^{n-1}\left|y-T^{k} y\right|_{n} \geqslant\left|y-\frac{1}{n} \sum_{k=0}^{n-1} T^{k} y\right|_{n} \geqslant|y|_{n}-\|\left.\left|\sum_{k=1}^{n} y_{k}\right||>| y\right|_{n}-t .
$$

The second inequality follows from

$$
\left|\sum_{k=0}^{n-1} T^{k} y\right|_{n}=\left|\left(\sum_{1}^{n} y_{k}, \ldots, \sum_{1}^{n} y_{k}\right)\right|_{n}=n\left\|\sum_{1}^{n} y_{k}\right\| .
$$

This implies (i) for some $k, k \in\{0,1 \ldots, n-1\}$.

(ii) We have according to (i):

$$
\begin{aligned}
\left|z-T^{k} z\right|_{n} & =\left|z-y+y-T^{k} y+T^{k} y-T^{k} z\right|_{n} \geqslant\left|y-T^{k} y\right|_{n}-|z-y|_{n}-\left|T^{k} y-T^{k} z\right|_{n} \\
& \geqslant|y|_{n}-t-C t-\left|T^{k} y-T^{k} z\right|_{n} .
\end{aligned}
$$

Putting in the last term $u=y-z$, we get using the fact that $\sum_{1}^{n} u_{i}=0$ :

$$
\begin{aligned}
\left|T^{k}(u)\right|_{n} & =\left|\left(u_{n-k+1}, u_{n-k+2}, \ldots, u_{n}, u_{1}, u_{2}, \ldots, u_{n-k}\right)\right|_{n} \\
& \leqslant \max _{1 \leqslant k \leqslant l \leqslant n}\left\|\sum_{i=k}^{l} u_{i}\right\| \leqslant 2|u|_{n}=2|y-z|_{n} .
\end{aligned}
$$

Now (4.1) gives

$$
\left|z-T^{k} z\right|_{n} \geqslant|y|_{n}-t-C t-2|y-z|_{n} \geqslant|y|_{n}-(3 C+1) t .
$$

To get (ii) we use the fact that $|y-z|_{n}<C t$.

Let us introduce necessary notation: Given $\theta=\left(\theta_{1}, \ldots, \theta_{n}\right) \in \Theta_{n}$ we put

$$
\{+\}=\left\{i: \theta_{i}=+1\right\}, \quad\{-\}=\left\{i: \theta_{i}=-1\right\} .
$$

For each $y=\left(y_{1}, \ldots, y_{n}\right) \in X^{n}$ put

$$
y^{+}=y_{i} I_{\{+\}}(i), \quad y^{-}=y_{i} I_{\{-\}}(i), \quad i=1, \ldots, n .
$$

Given $x=\left(x_{1}, \ldots, x_{n}\right)$ with $\sum_{1}^{n} x_{i}=0$ define

$$
\mathscr{A}=\left\{x_{\pi}: \pi \in \Pi_{n}\right\}, \quad \mathscr{A}_{x}=\left\{x_{\pi}: \pi \in \Pi_{n}, x_{\pi}^{+}=x^{+}\right\}, \quad \Lambda_{x}=\left\{z \in \mathscr{A}_{x}:|z \theta|_{n}<t\right\} .
$$


Lemma 3. There exists an injection $S: \Lambda_{x} \rightarrow \mathscr{A}_{x}$ such that

$$
\left|(S z)^{-}-z^{-}\right|_{n} \geqslant\left|z^{-}\right|_{n}-8.5 t, \quad z \in \Lambda_{x} .
$$

$\mathrm{P} \mathrm{r}$ o o f. Let $z \in \Lambda_{x}$. We claim that

$$
\left\|\sum_{i \in\{-\}} z_{i}^{-}\right\|<\frac{t}{2}
$$

Indeed, since $z \in \Lambda_{x}$, we have

$$
\left\|\sum_{\{-\}} z_{i}^{-}-\sum_{\{+\}} z_{i}^{+}\right\| \leqslant t ; \quad\left\|\sum_{\{-\}} z_{i}^{-}+\sum_{\{+\}} z_{i}^{+}\right\|=0 .
$$

These relations imply (4.3). We also have for $y \in \Lambda_{x}$

$$
\left|y^{-}-z^{-}\right|_{n}=|z \theta-y \theta|_{n} \leqslant|y \theta|_{n}+|z \theta|_{n} \leqslant 2 t .
$$

According to Lemma 2, for the cyclic permutation $T$ of $\{-\}$, some integer $k \leqslant \operatorname{card}\{-\}$ and any $z \in \Lambda_{x}$ restricted to $\{-\}$ the following inequality holds:

$$
\left|z^{-}-T^{k} z^{-}\right|_{n} \geqslant\left|z^{-}\right|_{n}-8.5 t \text {. }
$$

(the role of $t$ in Lemma 2 here is played by $t / 2$, while that of $C$ by 4 ). Finally let us put for any $z \in \Lambda_{x}:(S z)_{i}=x_{i}$, if $i \in\{+\}$ and $(S z)_{i}=\left(T^{k}\left(z^{-}\right)\right)_{i}$, if $i \in\{-\}$.

Lemma 4. Let $\Lambda=\left\{z \in \mathscr{A}:|\theta z|_{n}<t\right\}$. There is a mapping $U: \Lambda \rightarrow \mathscr{A}$ such that $U$ is an injection and satisfies the following conditions:

$$
\left|z^{-}-(U z)^{-}\right|_{n} \geqslant\left|z^{-}\right|_{n}-8.5 t \text { and }(U z)^{+}=z^{+}, \quad z \in \Lambda .
$$

P r o o f. Obviously we can find a collection $x^{1}, \ldots, x^{k} \in \mathscr{A}$ such that $\Lambda=\cup_{i=1}^{k} \Lambda_{x^{i}}$, where $\Lambda_{x^{i}} \cap \Lambda_{x^{j}}=\varnothing, i \neq j$. By Lemma 3 we have for any $i, 1 \leqslant i \leqslant k$, a mapping $T_{i}: \Lambda_{x^{i}} \rightarrow \mathscr{A}_{x^{i}}$ satisfying (4.2). Finally we define

$$
U(z)=T_{i}(z), \quad z \in \Lambda_{x^{i}} .
$$

Lemma 5. For every collection of signs $\theta=\left(\theta_{1}, \ldots, \theta_{n}\right)$ and any $t \geqslant 0$ the following inequality holds:

$$
\mathbf{P}\left(\left|x_{\pi}\right|_{n} \geqslant 22 t,\left|\theta x_{\pi}\right|_{n}<t\right) \leqslant \mathbf{P}\left(\left|\theta x_{\pi}\right| \geqslant t\right) .
$$

$\mathrm{P}$ r o o f. We need to show that if $z \in \Lambda$ satisfies $|z|_{n} \geqslant 22 t$, then $|\theta \cdot U(z)|_{n} \geqslant t$. We calculate using Lemma 4:

$$
|\theta \cdot U(z)|_{n}=\left|z^{+}-(U z)^{-}\right|_{n} \geqslant\left|z^{-}-(U z)^{-}\right|_{n}-t \geqslant\left|z^{-}\right|_{n}-9.5 t \geqslant 10.5 t-9.5 t=t,
$$

where the last inequality is a consequence of $\left|z^{+}+z^{-}\right|_{n} \geqslant 22 t$ and $\left|z^{+}-z^{-}\right|_{n}<t$, because they imply $\left|z^{-}\right|_{n} \geqslant 10.5 t$.

The following lemma follows from Lemma 5 and actually is the left-hand side inequality of Theorem $2^{\prime}$.

Lemma 6. For every collection of signs $\theta=\left(\theta_{1}, \ldots, \theta_{n}\right)$ and any $t \geqslant 0$ the following inequality holds:

$$
\mathbf{P}\left(\left|x_{\pi}\right|_{n} \geqslant 22 t\right) \leqslant 2 \mathbf{P}\left(\left|\theta \cdot x_{\pi}\right| \geqslant t\right) .
$$

$\mathrm{P}$ r o o f. Lemma 5 gives

$$
\begin{aligned}
& \mathbf{P}\left(\left|x_{\pi}\right|_{n} \geqslant 22 t\right)=\mathbf{P}\left(\left|x_{\pi}\right|_{n} \geqslant 22 t,\left|\theta \cdot x_{\pi}\right|<t\right)+\mathbf{P}\left(\left|x_{\pi}\right|_{n} \geqslant 22 t,\left|\theta \cdot x_{\pi}\right|_{n} \geqslant t\right) \\
& \quad \leqslant \mathbf{P}\left(\left|\theta \cdot x_{\pi}\right|_{n} \geqslant t\right)+\mathbf{P}\left(\left|x_{\pi}\right|_{n} \geqslant 22 t,\left|\theta \cdot x_{\pi}\right|_{n} \geqslant t\right) \leqslant 2 \mathbf{P}\left(\left|\theta \cdot x_{\pi}\right|_{n} \geqslant t\right) .
\end{aligned}
$$

Theorem 2 is proved.

In conclusion let us give a curious consequence of Theorem 2 . 

Then

Corollary. Let $x=\left(x_{1}, \ldots, x_{n}\right)$ be a collection of elements of $X$ with $\sum_{1}^{n} x_{i}=0$.

(i) There are universal constants $C_{1}>0$ and $C_{2}>0$ such that for any two collections $\theta=\left(\theta_{1}, \ldots, \theta_{n}\right) \in \Theta_{n}$ and $\varepsilon=\left(\varepsilon_{1}, \ldots, \varepsilon_{n}\right) \in \Theta_{n}$ the following inequality holds:

$$
\mathbf{P}\left\{\pi:\left|x_{\pi} \theta\right|>t\right\} \leqslant C_{1} \mathbf{P}\left\{\pi:\left|x_{\pi} \varepsilon\right|>\frac{t}{C_{2}}\right\} .
$$

(ii) There are universal constants $C_{1}$ and $C_{2}$ such that for any $t>0$ and any $\theta=$ $\left(\theta_{1}, \ldots, \theta_{n}\right) \in \Theta_{n}$

$$
\frac{1}{2} \mathbf{P}\left\{\pi:\left|x_{\pi}\right|>2 t\right\} \leqslant \mathbf{P}\left\{\omega:\left\|\sum x_{k} r_{k}\right\|>t\right\} \leqslant C_{1} \mathbf{P}\left\{\pi:\left|x_{\pi} \theta\right|>\frac{t}{C_{2}}\right\},
$$

where $r_{1}, \ldots, r_{n}$ is a system of Rademacher random variables.

\section{REFERENCES}

1. Kadets M.I., Kadets V.M. Series in Banach Spaces. Conditional and Unconditional Convergence. Boston: Birkhauser, 1997, 156 p.

2. Левенталь Ш., Мандрекар В.С., Чобанян С.A. К тереме Никишина о перестановочной сходимости почти наверное функциональных рядов. - Функц. анализ и его прил., 2011, т. 45 , в. 1, с. 41-55.

3. Кашин Б. С., Саакян А.А. Ортогональные ряды. М.: Наука, 1984.

4. Bourgain J. On Kolmogorov's rearrangement problem for orthogonal systems and Garsia's conjectures. — Lecture Notes Math., 1989, v. 1376, p. 209-250.

5. Konyagin $S$. V. On uniformly convergent rearrangements of trigonometric Fourier series. - J. Math. Sci., 2008, v. 155, № 1, p. 81-88.

6. Révész Sz. Gy. Rearrangement of Fourier series and Fourier series whose terms have random signs. - Acta Math. Hungar., 1994, v. 63, № 4, p. 395-402.

7. Chobanyan S. A., Giorgobiani G., Tarieladze V.I. Signs and permutations: two problems of function theory. - Proc. A Razmadze Math. Inst., 2012, v. 160, p. 25-34.

8. Sevast'yanov $S$. V. On some geometric methods in scheduling theory, a survey. Discrete Appl. Math., 1994, v. 55, p. 59-82.

9. Кадеи М. И. Об условно сходящихся рядах в пространстве $L^{p}$. - Успехи матем. наук, 1954, т. 59, в. 9, с. 107-109.

10. Garsia A. Existence of almost everywhere convergent rearrangements for Fourier series of $L_{2}$ functions. - Ann. Math., 1964, v. 22, p. 286-309.

11. Garsia A. Topics in Almost Everywhere Convergence. Chicago: Markham, 1970.

12. Maurey B., Pisier G. Remarques sur l'exposé de P. Assouad, «Espaces $p$-lisses, réarrangements». Paris: Séminaire Maurey-Schwartz 1974-1975, Annexe 1, Centre Math., École Polytech., 1975.

13. Chobanyan S. A. Convergence a.s. of rearranged series in Banach spaces and associated inequalities, Probability in Banach spaces, 9: Proc. of 9th International Conference on Probability in Banach Spaces (Sandbjerg, 1993). Boston, MA: Birkhäuser, 1994, p. 3-29.

14. Chobanyan S., Salehi H. Exact maximal inequalities for exchangeable systems of random variables. - Теория вероятн. и ее примен., 2000, т. 45, в. 3, с. 555-567.

15. Levental $S$. Permutations, signs and the Brownian bridge. - Stat. Probab. Letters, 2000, v. 46, № 3, p. 271-276.

16. Levental $S$. A maximal inequality for real numbers with application to exchangeable random variables. - Теория вероятн. и ее примен., 2000, т. 45, в. 3, с. 615-621.

Поступила в редакцию

11.VIII.2011

Исправленный вариант 30.VI.2014 